\title{
PENERAPAN SCHOOLOGY SEBAGAI LEARNING MANAGEMENT SYSTEM BAGI GURU SMAN 1 SUTERA
}

\author{
Jefril Rahmadoni *), Adi Arga Arifnur, dan Ullya Mega Wahyuni \\ Fakultas Teknologi Informasi Universitas Andalas \\ ${ }^{*}$ Email: jefrilrahmadoni@it.unand.ac.id
}

\begin{abstract}
ABSTRAK
Kegiatan ini bertujuan untuk memberikan metode pembelajaran yang lebih praktis, inovatif dan efisien yang disesuaikan dengan perkembangan teknologi informasi di era revolusi industri 4.0 dengan memanfaatkan media Learning Management System (LMS) gratis yaitu Schoology. Proses pembelajaran dalam LMS ini menggabungkan beberapa konten di dalam satu aplikasi yang dikemas dalam bentuk interaktif seperti flash maupun animasi, video pembelajaran, tugas maupun ujian dengan berbagai fitur diantaranya course content yang mencakup artikel, materi modul. Oleh karena itu, kami dari Program Studi Sistem Informasi Universitas Andalas bertujuan melakukan sosialisai pemanfaat teknologi informasi dalam proses belajar mengajar dengan LMS Schoology di SMAN 1 Sutera. Sebagai sekolah terbaik di Kabupaten Pesisir Selatan, SMAN 1 Sutera telah dilengkapi fasilitas penunjang proses belajar mengajar yang bisa memanfaatkan teknologi informasi. Subyek dari pengabdian ini adalah semua guru SMAN 1 Sutera, dimana para guru diberikan pelatihan dalam penggunaan Schoology agar dapat menerapkan proses belajar mengajar berbasis teknologi informasi. Metode pelaksanaan kegiatan ini dilakukan dalam lima tahap yaitu survey awal, perencanaan, persiapan, pelatihan dan evaluasi. Selama pelatihan berlangsung, antusias guru cukup tinggi dengan memberikan tanggapan positif sebesar $90 \%$ dari peserta serta memberikan respon bahwa Schoology merupakan alternatif lain untuk proses pembelajaran yang menarik. Dan sisanya masih belum terbiasa menggunakan teknologi dalam proses pembelajaran dikarenakan faktor usia.
\end{abstract}

Kata Kunci: Schoology, Learning Management System, E-Learning

\section{Schoology's Training as a Learning Management System for Teachers at SMAN 1 Sutera}

\begin{abstract}
This community service aims to provide more practical, innovative and efficient learning methods that are adapted to the development of information technology in the era of the industrial revolution 4.0 by utilizing the free Learning Management System (LMS) media, namely Schoology. The learning process in this LMS combines some content in one application that is packaged in an interactive form such as flash or animation, learning videos, assignments and examinations with various features including course content which includes articles, module materials. Therefore, we from the Andalas University Information Systems Study Program aim to socialize the utilization of information technology in the teaching and learning process with LMS Schoology at SMAN 1 Sutera. As the best school in Pesisir Selatan District, SMAN 1 Sutera has been equipped with facilities to support teaching and learning processes that can utilize information technology. The subjects of this dedication are all the teachers of SMAN 1 Sutera, where the teachers are given training in the use of Schoology in order to be able to apply the learning process based on information technology. The method of carrying out this activity is carried out in five stages: initial survey, planning, preparation, training and evaluation. During the training, the enthusiasm of the teacher was quite high by giving a positive response of $90 \%$ of the participants and responding that Schoology was another alternative for an interesting learning process. And the rest are not yet accustomed to using technology in the learning process due to age.
\end{abstract}

Keywords: Schoology, Learning Management System, E-Learning 


\section{PENDAHULUAN}

Perkembangan teknologi dalam bidang informasi sudah banyak memberikan dampak positif bagi kehidupan, salah satunya dalam bidang pendidikan (Putra et al., 2019). Pengajar seperti guru merupakan profesi yang bertugas melaksanakan pendidikan di suatu sekolah dasar maupun sekolah menengah dengan menggunakan berbagai metode pembelajaran demi memenuhi target pembelajarannya. Seorang guru di zaman sekarang dituntut mampu untuk berkreasi dalam mengembangkan metode pembelajaran dalam rangka meningkatkan minat belajar peserta didik dan mampu memanfaatkan kemajuan dan kecanggihan teknologi terutama teknologi informasi (Chodzirin, 2016).

Beberapa guru di SMAN 1 Sutera masih ada yang menggunakan model pengajaran tradisional atau konvensional yang seringkali mengharuskan guru berdiri di depan kelas sambil menerangkan mata pelajarannya. Tidak jarang pula guru menghabiskan banyak kertas saat membuat soal tugas, kuis maupun ujian untuk siswanya. Belum lagi permasalahan pada siswa yang tidak bisa mengikuti pelajaran dikarenakan beberapa hal seperti izin atau sakit sehingga mengakibatkan siswa tersebut ketinggalan salah satu atau beberapa materi mata pelajaran. Oleh karena itu, guru butuh revolusi teknologi pembelajaran seperti e-learning untuk meningkatkan efektifitas dan efisiensi proses belajar mengajar di sekolah.

E-learning merupakan bagian atau salah satu contoh penggunaan atau penerapan teknologi informasi dan komunikasi dalam proses pembelajaran (Nugroho, 2008). Melalui teknologi ini, guru dapat mengajar di depan sebuah komputer yang ada di suatu tempat, sedangkan para siswa mengikuti pelajaran tersebut dari komputer lain di tempat yang berbeda pada saat yang bersamaan maupun tidak bersamaan (Raharja, et al., 2011).

Learning Management System (LMS) merupakan salah satu bentuk perangkat lunak yang mengimplementasikan konsep electronic learning (Ni'am, 2013). LMS memungkinkan penyelenggaraan pendidikan bisa dengan mudah menerapkan $e$ learning pada lembaganya (Muhammad, 2017). LMS adalah aplikasi perangkat lunak untuk kegiatan online, program pembelajaran elektronik (e-learning program) dan isi pelatihan (Wibowo, et al., 2014). Dengan menggunakan $L M S$, dosen/guru/instruktur dapat mengelola program/kelas dan bertukar informasi dengan siswa (Putri, 2018). Salah satu contoh LMS adalah Schoology.

Schoology merupakan platform inovatif yang dibangun di atas inspirasi dari Facebook (antarmuka dan modelnya, aspek mendasar dengan hadirnya post, update status, berbagi dan memperbarui instan) dan dengan tujuan yang tepat untuk menjadi alat belajar (Tigowati, et al., 2017). Dengan adanya schoology diharapkan siswa dapat mengunduh materi pelajaran, slide presentasi, video tutorial, game, mengerjakan quis, ujian, diskusi, dan pengumpulan tugas yang diberikan oleh pengajar (Murni, 2016).

Menurut (Aminoto, 2014), adapun fitur-fitur yang dimiliki schoology adalah Courses (Kursus), yaitu fasilitas untuk membuat kelas mata pelajaran, Groups (Kelompok), yaitu fasilitas untuk membuat kelompok, Resources (Sumber Belajar), dalam fitur resource dapat menambahkan materi yaitu berupa: assignment, test/quiz, file/link, discussion, page, dan media album. 
Berdasarkan hasil penelitian dari (Tigowati, et al., 2017) menjelaskan beberapa kelebihan dari Schoology antara lain: a) Schoology menyediakan lebih banyak pilihan resources daripada yang disediakan oleh Edmodo. b) Schoology dapat menampung jenis soal (question bank) yang akan digunakan saat kuis. c) Schoology menyediakan fasilitas attandance absensi yang digunakan untuk mengecek kehadiran siswa. d) Schoology juga menyediakan fasilitas analityc untuk melihat semua aktivitas siswa pada setiap course, assignment, discussion dan aktivitas lain yang disiapkan untuk siswa. Schoology memiliki spesifikasi lebih lengkap dibandingkan dengan edmodo dan moodle. Schoology sangatlah lengkap dengan berbagai alat pembelajaran seperti dilakukan di dunia nyata, mulai dari pengecekan kehadiran, tes, kuis, hingga pengumpulan tugas peserta didik.

Schoology ini dikenalkan ke masyarakat dalam bentuk pelatihan. Kegiatan ini adalah bentuk kepedulian terhadap bidang pendidikan khususnya pengenalan teknologi informasi bagi masyarakat khususnya guru dengan melibatkan mahasiswa Laboratorium Enterprise Applications Jurusan Sistem Informasi.

Sebagai salah satu universitas yang ada di Sumatera Barat, Universitas Andalas memiliki dua jurusan yang melaksanakan pendidikan khusus teknologi informasi. Jurusan Sistem Informasi adalah salah satunya. Jurusan ini berperan sebagai wadah penampung aspirasi mahasiswa Sistem Informasi dalam pengembangan dan penerapan teknologi informasi. Tidak hanya berperan di dalam lingkungan kampus tetapi juga berperan dalam pengembangan teknologi khususnya bidang pengaplikasian teknologi Informasi di luar lingkungan kampus. Maka dari itu kami merancang sebuah kegiatan pengabdian kepada masyarakat.

Kegiatan ini bertujuan untuk memperkenalkan kepada guru tentang inovasi pembelajaran dengan memanfaatkan teknologi informasi sekaligus pengenalan jurusan sistem informasi di SMAN 1 Sutera. Kegiatan ini akan berlangsung di SMAN 1 Sutera dalam bentuk pelatihan sekaligus demo penggunaan schoology. Dengan adanya pelatihan ini diharapkan para guru mendapatkan pengetahuan praktis tentang cara menggunakan LMS Schoology.

\section{METODE}

Tujuan akhir kegiatan ini adalah memberi kemudahan bagi para guru yang ada di SMAN 1 Sutera dalam proses pembelajaran dengan memanfaatkan aplikasi Schoology yang lebih praktis, inovatif dan efisien. Agar pelaksanaan kegiatan ini berjalan dengan baik, maka perlu adanya perencanaan sehingga tujuan yang diinginkan tercapai. Oleh karena itu tahapan metode penelitian lapangan yang digunakan sebagai berikut :

1. Survei Awal

Tahapan ini dilakukan dengan menganalisa kebutuhan guru SMAN 1 Sutera tentang bagaimana cara mendigitalisasi pengelolaan nilai siswa oleh guru, dan memanfaatkan teknologi dalam proses belajar mengajar. Tahap ini dilakukan dengan melakukan survey awal ke SMAN 1 Sutera untuk mengetahui kebutuhan guru serta menetapkan waktu pelaksanaannya. 
2. Perancangan Kegiatan

Berdasarkan analisis kebutuhan pada tahapan sebelumnya, selanjutnya perlu dirancang kegiatan yang akan diselenggarakan dalam transfer of knowledge. Tahap ini juga dirumuskan daftar kebutuhan kegiatan dalam bentuk proposal rencana kegiatan.

3. Persiapan

Tahapan selanjutnya adalah melakukan persiapan pelatihan meliputi pembuatan materi pelatihan, perbanyakan modul dan koordinasi dengan pihak sekolah terkait kegiatan pelatihan yang akan diselenggarakan.

4. Pelatihan (on the job training)

Para guru dilatih tentang pendekatan yang baru dalam proses belajar mengajar dengan supervise langsung oleh seorang pelatih yang berpengalaman yaitu dosen yang memiliki keahlian di bidang pengajaran teknologi. Dengan metode ini peserta akan menerima representasi tiruan suatu aspek organisasi untuk menanganinya ketika di dalam kelas nanti.

5. Evaluasi

Pada tahapan ini akan dilakukan evaluasi terhadap pelatihan yang telah diberikan kemudian tim pengabdian akan memberikan penilaian serta masukan agar pemanfaatan schoology dapat berjalan dengan baik untuk yang akan datang.

Pelaksanaan kegiatan ini pada SMAN 1 Sutera akan dilaksanakan selama 2 bulan. Jadwal pelaksanaan kegiatan ini berdasarkan metode penelitian yang digunakan dapat dilihat pada Tabel 1 .

Tabel 1. Jadwal Pelaksanaan Kegiatan

\begin{tabular}{|c|c|c|c|c|c|c|c|c|c|}
\hline \multirow{2}{*}{ No } & \multirow{2}{*}{ Kegiatan } & \multicolumn{8}{|c|}{ Minggu ke- } \\
\hline & & 1 & 2 & 3 & 4 & 5 & 6 & 7 & 8 \\
\hline 1 & Survey Awal & & & & & & & & \\
\hline 2 & Perancanaan & & & & & & & & \\
\hline 3 & Persiapan & & & & & & & & \\
\hline 4 & Pelatihan & & & & & & & & \\
\hline 5 & Evaluasi & & & & & & & & \\
\hline
\end{tabular}

\section{HASIL DAN PEMBAHASAN}

Kegiatan di SMAN 1 Sutera ini bertujuan untuk memberikan metode pembelajaran yang lebih praktis, inovatif dan efisien sesuai perkembangan teknologi informasi yang berkembang dengan memanfaatkan media LMS sekolah gratis yaitu Schoology.

Untuk pelatihan Schoology bagi guru SMA N 1 Sutera telah dilaksanakan pada hari senin dan kamis, tanggal 14 dan tanggal 31 Oktober 2019. Pelaksanaan kegiatan ini diawali dengan melakukan kunjungan awal di SMAN 1 Sutera untuk 
mengkonfirmasikan program kegiatan dengan pihak sekolah yang diwakili oleh Kepala Sekolah dan Wakil Kurikulum selain itu tim pengabdian kepada masyarakat juga melakukan diskusi dengan beberapa guru untuk menganalisis situasi dan kebutuhan guru yang dibutuhkan dalam proses belajar mengajar serta menentukan waktu pelaksanaannya.

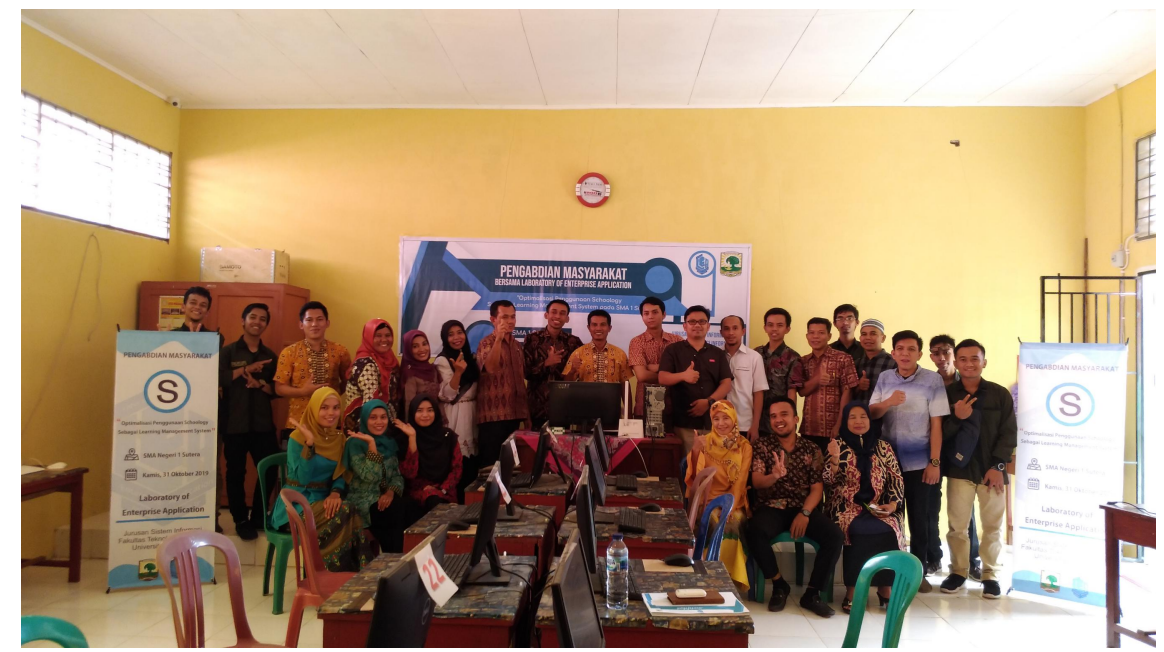

Gambar 1. Pelaksanaan Kegiatan di SMAN 1 Sutera

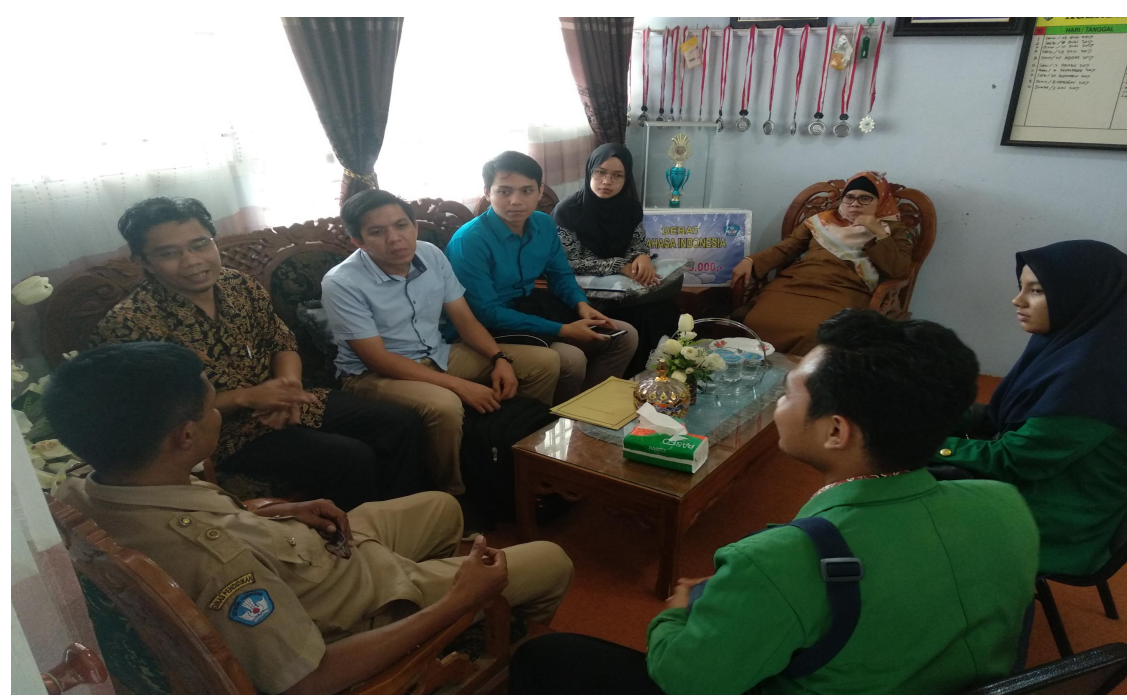

Gambar 2. Diskusi dengan Kepala Sekolah dan Guru SMAN 1 Sutera

Pelatihan yang diberikan berupa registrasi Schoology, dan bagaimana cara penggunaan schoology serta materi tentang pengetahuan LSM (Learning Managament System). Pelatihan dilaksanakan di Laboratorium Komputer SMA N 1 Sutera. Selama kegiatan berlangsung, antusias guru cukup tinggi terlihat dari rasa ingin tahu bagaimana proses implementasi dan pengelolaannya. Hal ini ditunjukkan dengan selama pelatihan berlangsung banyak pertanyaan yang muncul dari para guru tentang 
penggunaan Schoology ini. Pelatihan ini tidak hanya sekadar menjelaskan teori-teori, namun para guru langsung melakukan praktik yang dipandu oleh dosen dan mahasiswa.

Pelatihan inovasi pembelajaran berbasis LMS (Learning Managament System) dengan menggunakan aplikasi Schoology diharapkan dapat menunjang terlaksananya Pendidikan secara Go Internasional. Dengan memanfaatkan Schoology guru dan siswa bisa berinteraksi secara sosial sekaligus belajar karena schoology merupakan situs yang mengkombinasikan antara LMS dan jaringan media sosial. Untuk membuat kegiatan terstruktur, dibuat beberapa sesi pelatihan diantaranya:

1. Pembukaan

Pada sesi ini diawali berupa kata sambutan dari pihak sekolah dan Jurusan Sistem Informasi dan kemudian dilanjutkan penjelasan pengetahuan LSM bagi para guru oleh dosen dan diselingi diskusi antara dosen dan guru serta melibatkan pendapat mahasiswa yang ikut serta dalam program pengabdian untuk memberikan pandangan dan masukan mengenai pendidikan di era teknologi informasi ini.
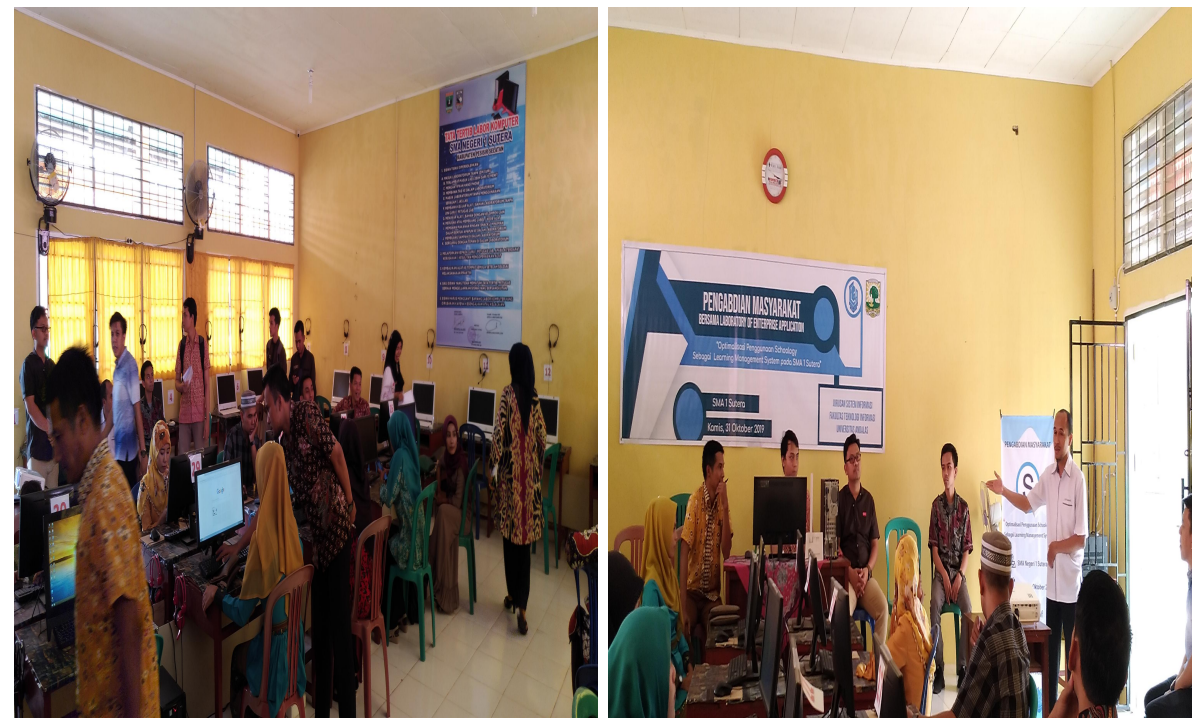

Gambar 3. Penjelasan Materi LMS yang disampaikan Dosen

2. Registrasi Schoology

Setelah diberikan pemahaman mengenai Learning Management System, para peserta diminta melakukan registrasi Schoology di komputer masing-masing untuk melanjutkan kelangkah selanjutnya. Registrasi berjalan dengan lancar yang mana sebelumnya para guru sudah membuat akun email atau jika sudah ada akun email harus masih aktif.

3. Pembuatan dan Penyetelan Akun

Peserta dipandu untuk membuat Mata Pelajaran dan penyetelan gradebook. Pada bagian ini masing-masing guru langsung membuat mata pelajaran sesuai yang mereka ajar, kemudia para guru membuat gradebook pada mata pelajaran yang sudah di buat. 


\section{Pengisian Konten}

Peserta dipandu untuk pengorganisasian mata pelajaran, unggah materi dan konten serta memasukkan siswa dan pengelompokan mahasiswa. Kemudian para guru juga membuat course yang nantinya bisa digunakan untuk memberikan tugas kepada para siswa. Pada bagian ini maerupakan bagian yang paling lama, para guru mengalami kesulitan dalam pengisian konten pada Schoology. Namun pada akhirnya semua guru dapat melakukan pengisian konten yang dibantu oleh mahasiswa dalam pelatihan tersebut.

5. Pengelolaan Proses Belajar Mengajar

Peserta dipandu untuk memposting pengumuman kepada siswa, membuat forum diskusi, rubrik, membuat tugas, kuis dan memberi nilai. Para guru sangat antusias dalam mengikuti pelatihan ini karena langsung pada praktik yang dipandu oleh dosen dan di bantu oleh mahasiswa.

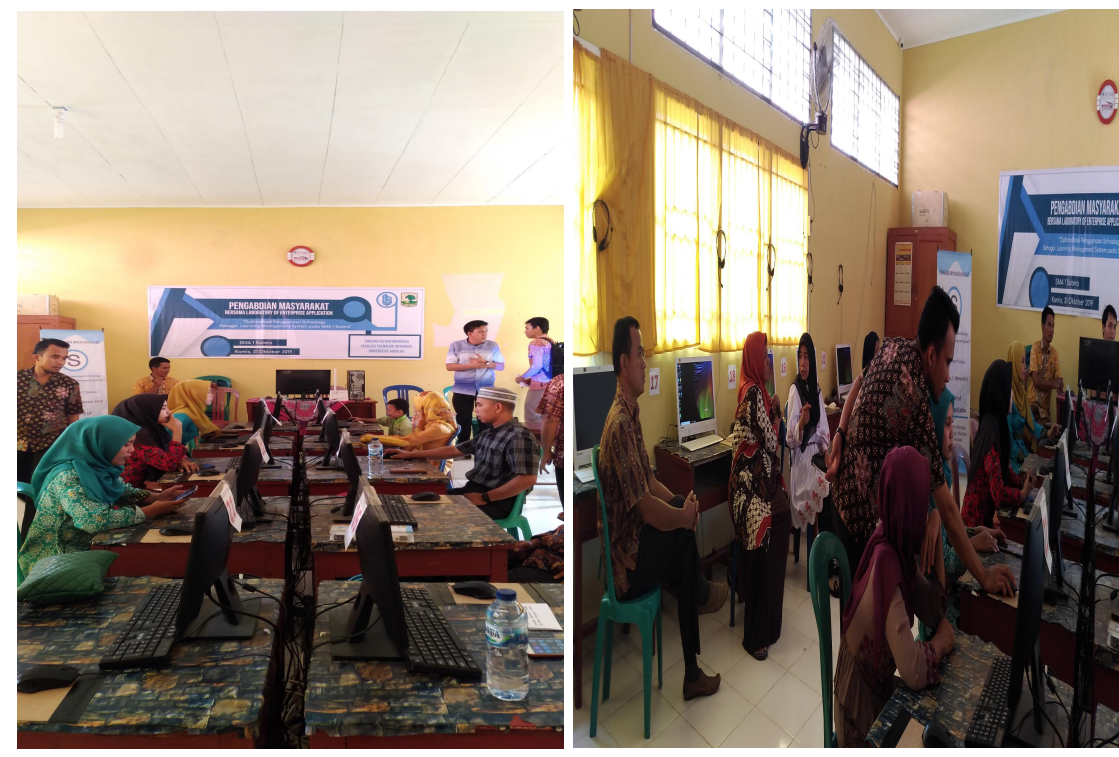

Gambar 4. Suasana Pelatihan Schoology di SMAN 1 Sutera

\section{KESIMPULAN DAN SARAN}

Program studi Sistem Informasi telah melaksanakan kegiatan ini yang dilakukan untuk mengenalkan metode pembelajaran berbasis teknologi informasi dengan memanfaatkan Learning Management System gratis yaitu Schoology untuk mendukung proses belajar mengajar di era revolusi industri 4.0. Selama pelatihan berlangsung, antusias guru cukup tinggi dengan memberikan tanggapan positif sebesar $90 \%$ dari peserta serta memberikan respon bahwa Schoology merupakan alternatif lain untuk proses pembelajaran yang menarik dan sisanya masih belum terbiasa menggunakan teknologi dalam proses pembelajaran dikarenakan faktor usia dari guru. Untuk saat ini, pelatihan ini hanya diberikan kepada guru SMAN 1 Sutera, kami berharap ke depannya 
bisa memberikan pelatihan kepada siswa dan orangtua sehingga penggunaan Schoology dapat dimanfaatkan secara maksimal.

\section{UCAPAN TERIMAKASIH}

Terima kasih kepada Fakultas Teknologi Informasi Universitas Andalas yang telah memberikan dana sehingga pengabdian ini bisa terlaksana dan juga terima kasih kepada segenap civitas akademik SMAN 1 Sutera atas kerjasamanya sehingga pelatihan ini bisa terlaksana dengan baik.

\section{DAFTAR PUSTAKA}

Aminoto, T. 2014. Penerapan media e-learning berbasis schoology untuk meningkatkan aktivitas dan hasil belajar materi usaha dan energi di kelas XI SMAN 10 Kota Jambi. Jurnal Sains dan Matematika Universitas Jambi. 8(1): 13-29.

Chodzirin, M. 2016. Pemanfaatan information and communication technology bagi pengembangan guru Madrasah Sub Urban. DIMAS. 16(2): 310-322.

Muhammad, Toufik. 2017. Perancangan learning management system menggunakan konsep computer supported collaborative learning. Jurnal PRODUKTIF. 1: $35-48$

Murni, C. K. 2016. Pengaruh e-learning berbasis schoology terhadap peningkatan hasil belajar siswa dalam materi perangkat keras jaringan kelas X TKJ 2 pada SMK Negeri 3 Buduran, Sidoarjo. Jurnal IT-Edu. 1(1): 86-90.

Ni'am, S. 2013. Pengembangan aplikasi learning management system (LMS) pada Sekolah Menengah Pertama Islam Terpadu (SMP IT) Harapan Bunda Semarang. Journal of Informatics and Technology. 2(1): 11-32.

Nugroho, A. A. 2008. Pemanfaatan e-learnng sebagai salah satu bentuk penerapan tik dalam proses pembelajaran. Majalah Ilmiah Pembelajaran, 4(2).

Putra, H., Hanim, H., \& Kartika, A. D. 2019. Implementasi pembelajaran berbasis teknologi informasi pada SMAN 1 Bukittinggi menggunakan schoology. Jurnal Hilirisasi IPTEKS. 2(4): 361-368.

Putri, D. D. 2018. Pengembangan learning management system menggunakan framework codeigniter dan angularjs di PT. XYZ. Jurnal Sistem Informasi. $14(1), 17-27$. 
Raharja, S., Prasojo, L. D., \& Nugroho, A. A. 2011. Model Pembelajaran berbasis learning management system dengan pengembangan software moodle di Sekolah Menengah Atas. Jurnal Kependidikan. 41(1): 34-44.

Tigowati, Efendi, A., \& Budiyanto, C. W. 2017. e-learning berbasis schoology dan edmodo: ditinjau dari motivasi dan hasil belajar siswa SMK. Elinvo (Electronics, Informatics and Vocational Education). 2(1): 49-59.

Wibowo, A. T., Akhlis, I., \& Nugroho, S. E. 2014. Pengembangan LMS (Learning Management System) berbasis web untuk mengukur pemahaman konsep dan karakter siswa. Scientific Journal of Informatics. 1(2): 127-137. 